\title{
Evaluation of the Use of Inhaled Medications by Hospital Inpatients with Chronic Obstructive Pulmonary Disease
}

\author{
Joshua Batterink, Karen Dahri, Amneet Aulakh, and Carmen Rempel
}

\begin{abstract}
Background: The prevalence of chronic obstructive pulmonary disease (COPD) is increasing. Patients with COPD are treated with a variety of inhaled medications. Previous studies evaluating inhaler technique have had varied results but have generally found high rates of misuse of these devices. There is a paucity of studies of inhaler technique focusing on North American patients with COPD who have been admitted to hospital.
\end{abstract}

Objective: To evaluate the inhaler technique of patients with COPD who have been admitted to hospital and to identify baseline patient characteristics and/or inhaler devices associated with poor inhaler technique.

Methods: Patients with a diagnosis of COPD who were admitted to the hospitalist or internal medicine service at a tertiary care hospital in British Columbia between October 2010 and April 2011 were identified. After giving informed consent, recruited patients demonstrated their inhaler technique, which was evaluated with standardized checklists. Errors in technique were categorized as either noncritical or critical. Critical errors were defined as those resulting in little or no medication reaching the lungs.

Results: Thirty-seven patients (mean age 78 years) participated in the study. Twenty-two (59\%) of the patients made critical errors while demonstrating their inhaler technique. Patients using metered-dose inhalers were more likely to make a critical error than patients using other inhalers (13/14 [93\%] versus 9/23 [39\%]; relative risk 2.38, $p=0.002)$. On average, $26 \%$ of the steps for using an inhaler were performed incorrectly. Twenty-three $(62 \%)$ of the patients reported having received previous counselling on inhaler technique, but only $13(57 \%)$ of these 23 patients had received such counselling in the previous 6 months.

Conclusions: More than half of the patients in this study misused their inhaler devices, and many made critical errors that would result in inadequate amounts of drug reaching the lung. Many of the patients were not receiving regular counselling on appropriate inhaler technique. Health care professionals should be aware of poor inhaler technique, should routinely evaluate their patients' inhaler technique, and should provide counselling.

Key words: chronic obstructive pulmonary disease, inhaler technique, metered-dose inhaler, Diskus inhaler, Turbuhaler inhaler

\begin{abstract}
RÉSUMÉ
Contexte : On observe une augmentation de la prévalence de la maladie pulmonaire obstructive chronique (MPOC). Les patients atteints d'une MPOC sont traités par divers médicaments en inhalation. Des études antérieures évaluant les techniques d'utilisation propres à chaque inhalateur ont dégagé divers résultats, mais ont généralement révélé un taux élevé d'utilisation inadéquate des inhalateurs. Il existe très peu d'études sur les techniques d'utilisation des inhalateurs menées spécifiquement chez des patients nord-américains atteints d'une MPOC et hospitalisés.
\end{abstract}

Objectif : Évaluer la technique d'utilisation des inhalateurs chez des patients atteints d'une MPOC qui ont été hospitalisés et déterminer les caractéristiques de départ des patients ou les dispositifs d'inhalation associés à une mauvaise technique d'utilisation.

Méthodes : On a repéré les patients affectés d'une MPOC qui ont été admis au service de médecine hospitalière ou au service de médecine interne d'un hôpital de soins tertiaires de Colombie-Britannique entre octobre 2010 et avril 2011. Après avoir accordé leur consentement éclairé, les patients recrutés ont montré leur technique d'utilisation de leur inhalateur, qui a été évaluée à l'aide de listes de contrôle standardisées. Les erreurs dans la technique d'utilisation ont été classées comme étant non critiques ou critiques. Les erreurs critiques étaient définies comme des erreurs ayant eu comme résultat que peu ou pas de médicament atteignait les poumons.

Résultats : Au total, 37 patients (âge moyen de 78 ans) ont participé à l'étude. De ces patients, 22 (59\%) ont fait des erreurs critiques lors de la démonstration de leur technique d'utilisation. Les patients qui utilisaient des aérosols-doseurs étaient plus susceptibles de faire des erreurs critiques que ceux utilisant d'autres inhalateurs (13/14 [93\%] contre 9/23 [39\%]; risque relatif de 2,38, $p=0,002$ ). En moyenne, $26 \%$ des étapes d'utilisation d'un inhalateur ont été effectuées incorrectement. Parmi les patients, $23(62 \%)$ ont indiqué avoir déjà reçu des conseils sur la technique d'utilisation de l'inhalateur, mais seulement 13 (57\%) de ces 23 patients avaient reçu des conseils dans les six derniers mois.

Conclusions: Plus de la moitié des patients de l'étude utilisaient incorrectement leur inhalateur, et beaucoup faisaient des erreurs critiques qui avaient comme résultat qu'une quantité inadéquate du médicament atteignait les poumons. Plusieurs des patients ne recevaient pas de façon régulière des conseils sur la technique d'utilisation appropriée de leur inhalateur. Les professionnels de la santé devraient être conscients des mauvaises techniques d'utilisation des inhalateurs, évaluer régulièrement la technique d'utilisation des inhalateurs de leurs patients et donner à ces derniers des conseils sur cette technique. 


\section{Can J Hosp Pharm 2012;65(2):111-118}

Mots clés: maladie pulmonaire obstructive chronique, technique d'utilisation des inhalateurs, aérosol-doseur, inhalateur Diskus, inhalateur Turbuhaler

[Traduction par l'éditeur]

\section{INTRODUCTION}

$\mathrm{C}$ hronic obstructive pulmonary disease (COPD) is common in elderly populations, and its prevalence has been on the rise in recent years. ${ }^{1}$ Treatment is currently limited to amelioration of symptoms through regimens consisting of one or more medications administered via inhalation. The inhalation route provides a wide therapeutic index, but burdens patients with issues of adherence and inhaler technique. In some COPD populations, fewer than half of the patients take more than $80 \%$ of their prescribed doses, and the detrimental effects of poor adherence are compounded by a high prevalence of poor inhaler technique. ${ }^{2}$

In previous studies, rates of inappropriate technique have ranged from $4 \%$ to $96 \% .{ }^{3,4}$ Although studies directly correlating negative COPD outcomes with poor inhaler technique are lacking, many investigators have shown that the deposition of inhaled medications is reduced or almost absent in the lungs of patients with poor inhaler technique.-8 However, previous studies have had numerous limitations. For example, most have included not only patients with COPD but also patients with asthma or nonspecific respiratory conditions, and most have been performed predominantly in the community setting. There is a lack of Canadian data characterizing COPD patients undergoing treatment in hospital.

The study reported here was designed to evaluate the inhaler technique of patients with COPD who were admitted to a large Canadian teaching hospital and to identify patient characteristics and/or particular inhaler devices associated with poor inhaler technique.

\section{METHODS}

\section{Study Participants}

The study was conducted from October 2010 to April 2011 at Vancouver General Hospital, Vancouver, British Columbia, a tertiary-care teaching hospital. The hospital's electronic medication profiles of patients admitted under the internal medicine or hospitalist service were reviewed to identify patients with prescriptions for inhaled medications. The investigators aimed to screen profiles weekly between the months of October and April. After all of the medication profiles for a given week had been screened, a random-order list of potentially eligible patients was generated. Potential participants were approached in the order specified in the list. Some potential participants were not seen because of time constraints and their unavailability when contact was attempted. Potential participants were screened according to prespecified inclusion and exclusion criteria, and patients who met the screening criteria were asked to provide informed consent to participate. The inclusion criteria were diagnosis of COPD and use of one or more inhaled medications for a minimum of 1 month before admission. Exclusion criteria were diagnosis of dementia or documented score of less than 23 on the Mini Mental State Examination, acute delirium or psychosis, decreased or altered level of consciousness, acute musculoskeletal injury impairing ability to use an inhaler, and inability to read or speak English with no translator available. Patients were eligible for the study regardless of when they had been admitted to the hospital and regardless of whether they were self-administering their inhaler medications in the hospital or were receiving assistance from nurses.

The study was approved by the Clinical Research Ethics Board of the University of British Columbia.

\section{Development of Checklists for Assessing Technique}

Checklists were developed for each of the 5 inhaler types available in Canada: metered dose inhaler (MDI), MDI with spacer, Turbuhaler (AstraZeneca Canada, Mississauga, Ontario), Diskus (GlaxoSmithKline, Mississauga, Ontario), and HandiHaler (Boehringer Ingelheim, Burlington, Ontario). Each inhaler checklist consisted of 7 to 9 steps that together were deemed to constitute correct inhaler technique. The steps in each checklist were derived from previously published inhaler checklists and manufacturers' recommendations. ${ }^{29-20}$ As has been done in previous studies, some steps of the checklists were defined as critical, with critical errors resulting from their incorrect execution (Box 1). Critical steps were those for which incorrect performance would lead to little or no medication reaching the lungs. ${ }^{10}$ The critical steps for each inhaler device were unique, but the majority were related to activating the inhaler or inhaling the medication. 
Box 1. Checklists for Correct Technique for Each of 5 Inhaler Devices*

MDI

1. Remove cap

2. Shake well

3. Breathe out normally

4. Keep head upright or slightly tilted

5. Seal lips around mouthpiece

6. Inhale slowly, actuating once during first half of inhalation

7. Continue slow and deep inhalation

8. Hold breath for 5 or more seconds

MDI with spacer

1. Remove caps

2. Shake MDI well

3. Insert MDI into spacer

4. Breathe out normally

5. Seal lips around mouthpiece

6. Actuate MDI

7. Inhale slowly and deeply

8. Hold breath for 5 or more seconds

Diskus

1. Open to expose mouthpiece

2. Slide lever until click heard

3. Keep level throughout

4. Breathe out normally and away from inhaler

5. Seal lips around mouthpiece

6. Inhale forcefully and deeply

7. Hold breath for 5 or more seconds

8. Exhale but not through inhaler

Turbuhaler

1. Hold upright without occluding air vents

2. Turn coloured wheel one way, then back

3. Breathe out normally and away from mouthpiece

4. Seal lips around mouthpiece without occluding air vents

5. Inhale forcefully and deeply

6. Hold breath for at least 5 seconds

7. Exhale but not through inhaler

HandiHaler

1. Open lid and mouthpiece

2. Place capsule in chamber

3. Close mouthpiece, ensuring click is heard

4. Holding inhaler upright, press blue button fully

5. Breathe out normally and away from inhaler

6. Seal lips around mouthpiece

7. Inhale forcefully and deeply so that capsule vibrates

8. Hold breath for 5 or more seconds

9. Repeat steps 6-8

$\mathrm{MDI}=$ metered-dose inhaler.

*Bold indicates steps that are critical, for which incorrect performance would lead to little or no medication reaching the lungs.

The checklists were assessed for inter-rater reliability as follows. Two investigators, one of whom subsequently assessed patients, simultaneously assessed the inhaler technique of 15 consecutive health care professionals. The health care profes- sionals participating in this aspect of the study did not have any underlying respiratory disease. All had previously received training on the proper use of the various inhalers but were not given any additional training before the assessment. The 2 investigators were both well trained in correct use of inhaler devices and had received additional training from another investigator (C.R.), a respiratory therapist. Overall agreement and Cohen's kappa were used to assess inter-rater reliability of checklists for identifying whether a patient made one or more critical errors, and Spearman's rho was used to assess inter-rater reliability for the percentage of steps performed correctly.

\section{Patient Recruitment}

One investigator (J.B.) interviewed patients who consented to participate to obtain baseline characteristics. The same investigator then performed all assessments of inhaler technique according to the previously developed checklists (Box 1). In addition to the baseline characteristics, patients were asked when and from whom they had most recently received counselling. The interview with the patient and assessment of inhaler technique followed a prespecified data collection form, to ensure that all necessary information was collected. To allow the patients to demonstrate their inhaler technique without exposure to unnecessary medication, each patient was given a placebo inhaler or a placebo capsule (for the HandiHaler device) with which to demonstrate technique. The assessor did not provide any guidance or feedback until the patient had finished demonstrating his or her technique with all of the inhaler types that he or she was using. Data from the interview and the assessment of inhaler technique were recorded on the data collection form and then transcribed into an electronic spreadsheet for analysis. The baseline characteristics collected during the interview did not affect how the patient's technique was subsequently assessed.

\section{Outcomes}

The primary outcome was the proportion of patients making at least one critical error. Secondary outcomes were the mean percentage of steps performed correctly and the interrater reliability of the checklists.

\section{Statistical Analysis}

All data analyses were performed by one of the investigators (J.B.). The target sample size was calculated to estimate the rate of the primary outcome with a precision of $10 \%$ at a confidence level of $95 \%$. We estimated that we would be drawing from a population of 400 eligible patients and thus would need 78 patients to be included in the analysis. For patients using more than one type of inhaler device before admission, inhaler technique for all devices was assessed; one inhaler device 


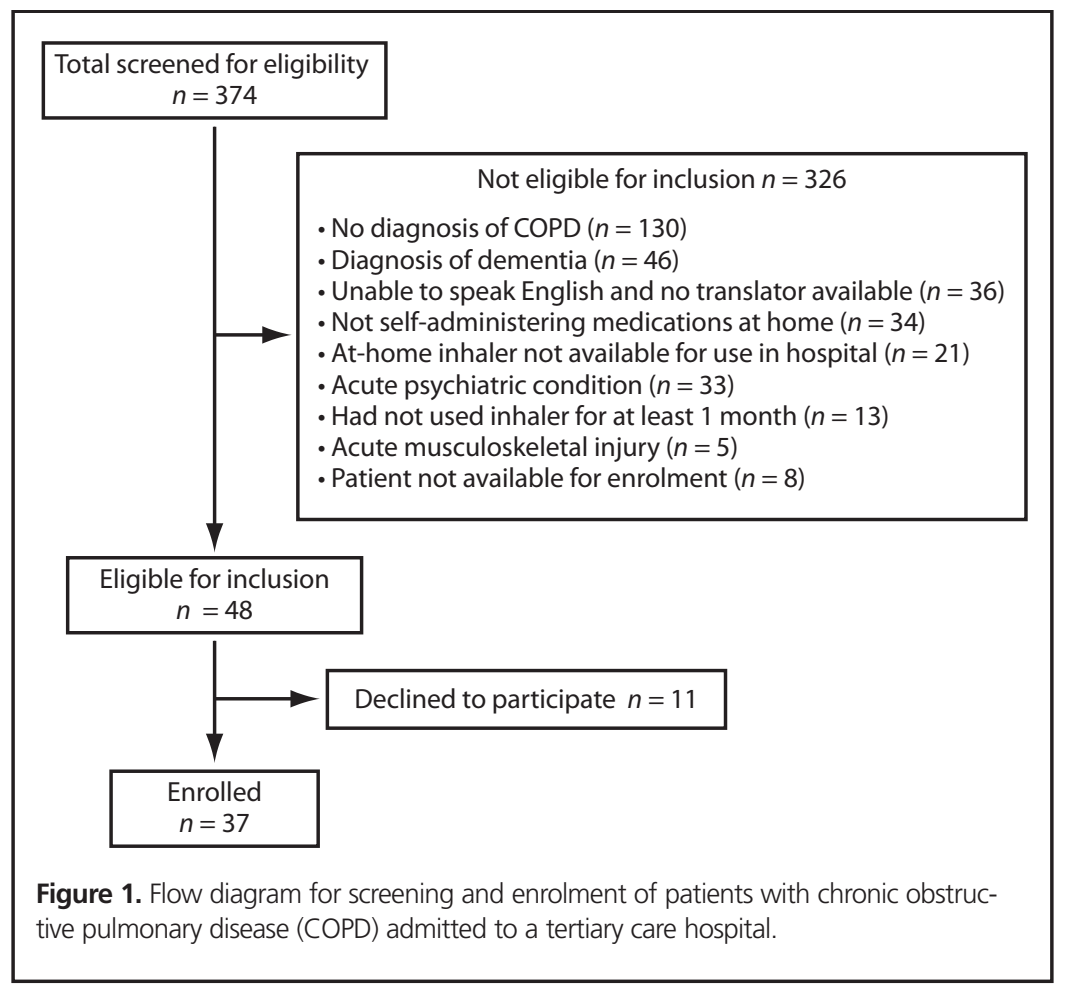

was then randomly selected and results for that device were used for determining the primary outcome. Data from a particular type of inhaler were analyzed together, regardless of whether patients were using them regularly or as needed. For assessing possible interactions between baseline characteristics and primary and secondary outcomes, categorical data were tabulated and compared using Fisher's exact test; continuous variables were compared using the Student $t$ test.

\section{RESULTS}

A total of 374 patients were screened, but only 48 patients were eligible for inclusion in this study (Figure 1). The ratio of patients screened to patients included was high because the method used to identify potential participants was not specific to patients with a diagnosis of COPD. Eleven of the 48 eligible patients declined to participate, so 37 patients were enrolled (Table 1). The mean age of participants was 78 years, and $22(59 \%)$ were women. The patients had been admitted for a variety of reasons, with only $16(43 \%)$ being admitted for acute exacerbation of COPD. Only $3(8 \%)$ of the patients did not speak English. The mean number ( \pm standard deviation) of different inhaled medications was $2.4 \pm 0.9$, and the mean number of different inhaler devices was $1.8 \pm 0.7$. Patients had used their inhalers for an average of $5.6 \pm 6.9$ years. The majority of the patients enrolled in the study had been in hospital for less than a week. For the majority of patients, hospital nursing staff were assisting with administration of inhaled medications.
Table 1. Characteristics of 37 Patients at Time of Enrolment

\begin{tabular}{lc} 
Characteristic & $\begin{array}{c}\text { No. (\%) of Patients } \\
\text { or Mean } \pm \text { SD }\end{array}$ \\
\hline Sex (no. [\%] women) & $22(59)$ \\
Age, mean (years) & 78 \\
Admitted for acute exacerbation of COPD & $16(43)$ \\
Language other than English & $3(8)$ \\
Smoking history (pack-years) & $45.1 \pm 26$ \\
Comorbidities & $33(89)$ \\
$\quad$ Cardiovascular & $11(30)$ \\
Neurological & $7(19)$ \\
Psychological & $8.8 \pm 3.2$ \\
No. of medications (all types) & $2.4 \pm 0.9$ \\
No. of inhaled medications & $1.8 \pm 0.7$ \\
No. of inhaler types & $5.6 \pm 6.9$ \\
Duration of inhaler use (years) & \\
\hline COPD = chronic obstructive pulmonary disease, \\
SD = standard deviation.
\end{tabular}

Overall, $22(59 \%)$ of the patients made critical errors while demonstrating inhaler technique, and on average patients performed $26 \%$ of all steps incorrectly (Table 2 ). The frequency of correct performance of individual steps for each inhaler is presented in Figure 2. Patients using the MDI were more likely to make a critical error than patients using other inhalers (13/14 [93\%] versus 9/23 [39\%]; relative risk [RR] 2.38, $p=0.002)$. There was no significant effect of inhaler type on the mean proportion of steps performed correctly. Patients' baseline characteristics were evaluated for interactions with 
Table 2. Occurrence of Critical Errors and Percentage of Incorrect Steps by Inhaler

\begin{tabular}{lcccccc} 
Outcome & $\begin{array}{c}\text { MDI } \\
(\boldsymbol{n}=\mathbf{1 4})\end{array}$ & $\begin{array}{c}\text { MDI with } \\
\text { Spacer }(\boldsymbol{n}=\mathbf{2})\end{array}$ & $\begin{array}{c}\text { Turbuhaler } \\
(\boldsymbol{n}=\mathbf{5})\end{array}$ & $\begin{array}{c}\text { Diskus } \\
(\boldsymbol{n}=\mathbf{1 0})\end{array}$ & $\begin{array}{c}\text { HandiHaler } \\
(\boldsymbol{n}=\mathbf{6})\end{array}$ & $\begin{array}{c}\text { All Inhalers } \\
(\boldsymbol{n}=\mathbf{3 7})\end{array}$ \\
\hline No. (\%) of patients with $\geq 1$ & $13(93)$ & $0(0)$ & $1(20)$ & $5(50)$ & $3(50)$ & $22(59)$ \\
critical error & 1.6 & 0 & 0.2 & 0.9 & 0.5 & 1.0 \\
Mean no. critical errors/patient & 34 & 22 & 14 & 28 & 13 & 26 \\
Mean \% of steps incorrect & & & & & & \\
\hline
\end{tabular}

$\overline{\mathrm{MDI}}=$ metered-dose inhaler.

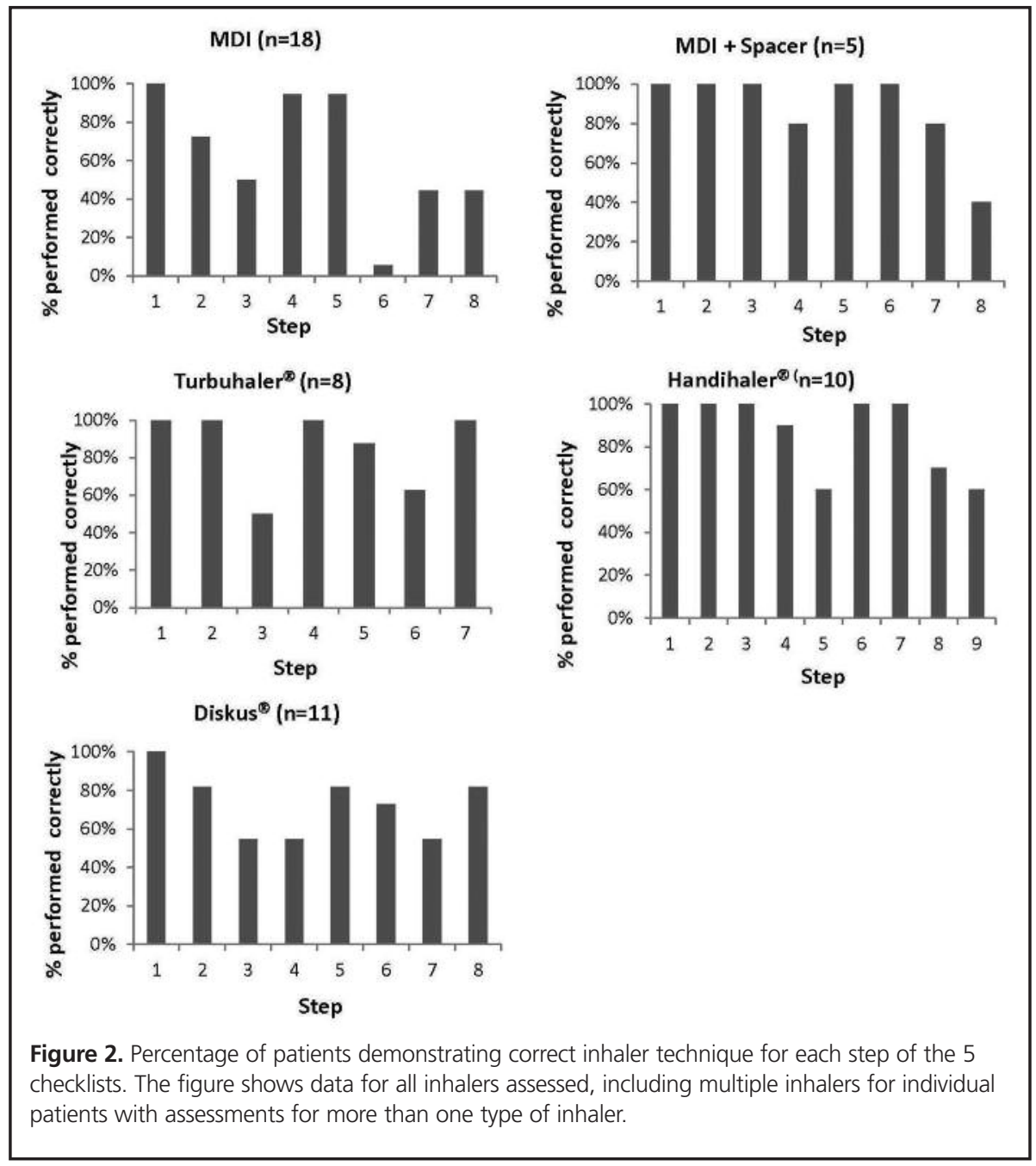

the rates of the primary and secondary outcomes, but few significant interactions were identified. Patients making a critical error were using significantly fewer inhaled medications at home (2.0 versus $2.9, p=0.003)$ and significantly fewer different types of inhalers ( 1.5 versus $2.1, p=0.012$ ), and they had used their inhalers for significantly longer periods of time (7.2 versus 3.2 years, $p=0.047$ ).

During the interviews, patients were asked when and from whom they had last received counselling on inhaler technique. Twenty-three (62\%) of the patients reported having received counselling, and $13(35 \%)$ had received counselling within the last 6 months. Of the 23 patients who had received counselling, $10(43 \%)$ had been counselled by a pharmacist and 13 (57\%) had been counselled by a respiratory therapist, physician, nurse, or respirologist. There were no significant interactions between previous counselling and the rates of primary or secondary outcomes.

The inter-rater reliability of the checklists is presented in Table 3. Agreement was high (greater than $80 \%$ ) for all inhaler checklists during assessment for the presence or absence of a critical error (Table 3). Kappa values were not consistently high, and the checklists for the MDI with spacer, the Diskus device, 


\section{Table 3. Inter-rater Reliability of Checklists}

\begin{tabular}{llcccc} 
Statistic & MDI & MDI with Spacer & Turbuhaler & Diskus & HandiHaler \\
\hline Overall agreement & 0.867 & 0.933 & 0.867 & 0.8 & 1 \\
Cohen's kappat & 0.42 & $0.86^{*}$ & -0.07 & $0.60^{*}$ & $1.00^{*}$ \\
Spearman's rhoł & $0.839^{*}$ & $0.673^{*}$ & $0.683^{*}$ & 0.324 & $0.564^{*}$ \\
\hline
\end{tabular}

$\mathrm{MDI}=$ metered-dose inhaler.

${ }^{*} p<0.05$.

tCohen's kappa is a measure of agreement that adjusts for chance agreement between observers. It is used with nominal data. Kappa values close to or below 0 indicate that agreement between observers is not at all or only slightly better than chance.

Kappa values above 0 indicate agreement better than chance. A kappa value of exactly 1 indicates perfect agreement.

¥Spearman's rho measures the association between observers and is used for continuous data. A value of 0 indicates no relation and a value of 1 indicates perfect relation.

and the HandiHaler device performed better than those for the MDI and the Turbuhaler device. Spearman's rho indicated moderate agreement between assessors for all inhalers except the Diskus device.

\section{DISCUSSION}

In this study, $59 \%$ of patients made one or more critical errors, a greater percentage than in previous studies, for which rates were between $19.8 \%$ and $40.1 \% .^{9-11,21,22} \mathrm{~A}$ number of factors may have contributed to the higher error rate. The current study recruited hospital inpatients with COPD, whereas previous studies were mostly performed in outpatient populations. It has been suggested that patients may exhibit poorer inhaler technique during acute illness because of delirium or various metabolic and inflammatory disorders. ${ }^{23}$ Alternatively, it may be that patients with poor inhaler technique are more likely to be admitted to hospital. Such patients may have concomitant diseases or poorly controlled COPD because of their poor inhaler technique or lack of medication adherence. Patients included in the current study were generally older than those in previous studies, ${ }^{10,11,21,22}$ and most, though not all, previous studies evaluating the effects of age on inhaler technique have found that older patients make significantly more errors in inhaler technique. ${ }^{11,12,21,22,24}$ Prior studies were not performed exclusively in patients with COPD and also included patients with other respiratory conditions. Patients with COPD have been found to make significantly more inhaler technique errors than patients with asthma, so it is to be expected that the error rate in the current study would be higher than in populations of patients with mixed respiratory conditions. ${ }^{25}$ With these factors in mind, the authors believe that the critical error rate identified in this study was accurate for the population studied and thus has potentially serious implications.

As in previous studies, significantly more patients using an MDI made more critical errors than patients using other inhaler devices. ${ }^{10,11}$ Nearly all patients who demonstrated their MDI technique made mistakes during the processes of actuating the inhaler and subsequently inhaling. These steps have previously been identified as problematic, since patients are consistently unable to coordinate actuation and inhalation. ${ }^{3}$ Some authors have suggested that patients cannot learn to perform these steps correctly without first watching a demonstration. ${ }^{26}$ However, health care professionals do not routinely demonstrate inhaler technique to patients, which may contribute to the high rate of errors with the MDI. ${ }^{27,28}$ Poor MDI technique cannot be ignored, as some medications are available only via this type of device. For patients who must use an MDI, it is reasonable to combine the device with a spacer and to provide regular counselling. Use of a spacer eliminates the need to coordinate actuation and inhalation, and there is evidence that the majority of patients using this type of device have appropriate technique. 'The results of the current study are concordant with this observation. Patients who are not willing to use a spacer may achieve acceptable technique with counselling that includes demonstration of inhaler technique and that is repeated at regular intervals. ${ }^{26}$

This study identified few baseline characteristics associated with increased rates of errors in inhaler technique. In contrast, previous studies found that poor inhaler technique was correlated with characteristics such as age, sex, and absence of prior counselling. ${ }^{11,12,21,22,24}$ The current study recruited fewer patients than anticipated, which may have resulted in insufficient power to identify interactions. Differences were identified between patients making and those not making a critical error, but the direction of the associations was unexpected. In particular, patients who made a critical error had significantly fewer inhaled medications and inhaler types at baseline and had been using their inhalers for longer periods of time. It had been anticipated that patients making a critical error would have more inhaled medications and inhaler types, which would make sense intuitively and which has been reported previously. ${ }^{10}$ These unexpected associations reinforce the ideas that any patient is at risk of having poor inhaler technique and thus that all patients using inhalers would benefit from regular review of their technique to ensure compliance and adequate delivery of drug.

In this study, $62 \%$ of patients reported that they had received previous counselling on inhaler technique, but only 
$35 \%$ of patients had received counselling within the past 6 months. This level of counselling is inconsistent with guideline recommendations suggesting that health care professionals ensure the correctness of inhaler technique at each visit and that inhaler technique counselling be included as part of disease management education for all patients. ${ }^{29,30}$ Several factors may have contributed to low counselling rates. Overestimation of the quality of inhaler technique is common. A study of physicians found that they frequently overestimated how well their patients were using inhalers, ${ }^{11}$ and in studies of patients the majority are confident about their inhaler technique, despite nearly all subsequently demonstrating at least one technique error. ${ }^{25}$ Health care professionals may not feel confident about counselling patients on how to use inhalers and may therefore avoid doing so. Improper inhaler technique is common among health care professionals from a variety of professional backgrounds, including respiratory therapists and pharmacists, who are commonly called upon to counsel patients. ${ }^{13,31,32}$ All health care professionals have a variety of responsibilities but only limited time to fulfill them. As no single health care profession is held accountable for ensuring that patients have appropriate inhaler technique, each can defer counselling in the hope that another will perform this task.

Only 10 patients in this study ( $27 \%$ of the entire sample) reported having previously receiving counselling from a pharmacist. Some authors have noted that pharmacists are in an ideal position to provide counselling on inhaler technique because they are trained to provide such counselling, they are readily accessible to patients, and they are typically the last health care professionals to see outpatients before they self-administer their medications. ${ }^{27}$ Efforts to improve the rate and quality of counselling by pharmacists may have a positive effect on patients' inhaler technique and may improve patients' outcomes while reducing system costs.

The preliminary assessment of inhaler checklists revealed high overall agreement (greater than $80 \%$ ), meaning that the 2 assessors in this part of the study usually agreed about whether there was a critical error. However, kappa values were not high for all of the checklists. Kappa values can be unreliable when one of the outcomes is much more prevalent than the other. ${ }^{33}$ Nearly all of the 15 health care professionals in this part of the study made a critical mistake when using the MDI, whereas almost none made a critical mistake when using the Turbuhaler. As a result, achieving a high kappa value was unlikely, regardless of the quality of the checklist. We avoided any potential effects of variations in assessments of patients by having a single assessor for that part of the study.

This study had some limitations that may reduce the accuracy and generalizability of the results. First, the adequacy of inspiratory flow was not objectively assessed. Inhalation that is too forceful may compromise the delivery of medication by the MDI, whereas the reverse is true for dry powder inhalers. ${ }^{34.36}$ Patients' inspiratory flow was assessed visually, but this form of assessment has been found to be less accurate than an objective monitoring system..$^{34}$ Fortunately, there is evidence suggesting that patients with COPD generally have adequate inspiratory flow for the Turbuhaler and Diskus inhalers. ${ }^{35,36}$ Additionally, the adequacy of inspiratory flow can be and was assessed for patients using the HandiHaler device, by noting the unique rattling sound that emanates from the device when inspiratory flow is adequate. ${ }^{3}$ In contrast, patients commonly have excessive inspiratory flow when using an MDI. ${ }^{36}$ Assessing inspiratory flow rate for patients using the MDI might have identified additional ways that patients were misusing their inhalers, but doing so could have affected the primary outcome only modestly, as most of these patients had already been identified as having poor inhaler technique.

The accuracy of the results may also have been limited by the Hawthorne effect, whereby people act differently when they are aware that they are being studied. ${ }^{37}$ In the current study, patients may have been motivated to demonstrate appropriate inhaler technique because their technique was being observed, which could have positively biased the results. Conversely, patients may have been less motivated to use their inhaler correctly because they knew they were not using a real medication. It is difficult to know how much and in what direction the Hawthorne effect might have affected our results.

The recruitment rate was slower than expected, which diminished the sample size. This in turn reduced the precision of the results and limited the ability to examine interactions between baseline characteristics, types of inhaler devices, and quality of inhaler technique.

Lastly, the study was limited by the unfortunate exclusion of some otherwise eligible patients who could not speak English. Although such patients were included when translators were available, this was generally not the case and, as a consequence, the study population was predominantly Englishspeaking. As such, inhaler technique among non-English speakers remains unevaluated, which again reduces the generalizability of these results.

\section{CONCLUSIONS}

The results of this study indicate a high prevalence of poor inhaler technique among patients with COPD, especially among patients using an MDI without a spacer. Patients with poor inhaler technique are at risk for uncontrolled respiratory disease, which may lead to escalation of medication doses, polypharmacy, and increased cost to both themselves and the health care system. In stark contrast to the frequency of inhaler misuse is the infrequency of regular counselling on inhaler technique. Health care professionals should be aware of this research and should focus on providing appropriate counselling 
on inhaler technique, in accordance with published guideline recommendations.

\section{References}

1. Gershon AS, Wang C, Wilton AS, Raut R, To T. Trends in chronic obstructive pulmonary disease prevalence, incidence, and mortality in Ontario, Canada, 1996 to 2007: a population-based study. Arch Intern Med 2010;170(6):560-565.

2. Mehuys E, Boussery K, Adriaens E, Van Bortel L, De Bolle L, Van Tongelen, et al. COPD management in primary care: an observational, community pharmacy-based study. Ann Pharmacother 2010;44(2):257-266.

3. Rau JL. Practical problems with aerosol therapy in COPD. Respir Care 2006;51(2):158-172.

4. Lavorini F, Magnan A, Dubus JC, Voshaar T, Corbetta L, Broeders M, et al. Effect of incorrect use of dry powder inhalers on management of patients with asthma and COPD. Respir Med 2008;102(4):593-604.

5. Hindle M, Chrystyn H. Relative bioavailability of salbutamol to the lung following inhalation using metered dose inhalation methods and spacer devices. Thorax 1994;49(6):549-553.

6. Hindle M, Newton DAG, Chrystyn H. Investigations of an optimal inhaler technique with the use of urinary salbutamol excretion as a measure of relative bioavailability to the lung. Thorax 1993;48(6):607-610.

7. Self TH, Pinner NA, Sowell RS, Headley AS. Does it really matter what volume to exhale before using asthma inhalation devices? J Asthma 2009;46(3):212-216

8. Engel T, Scharling B, Skovsted B, Heinig JH. Effects, side effects and plasma concentrations of terbutaline in adult asthmatics after inhaling from a dry powder inhaler device at different inhalation flows and volumes. $\mathrm{Br} \mathrm{J}$ Clin Pharmacol 1992;33(4):439-444.

9. Ho SF, O'Mahony MS, Steward JA, Breay P, Burr ML. Inhaler technique in older people in the community. Age Aging 2004;33(2):185-188.

10. van der Palen J, Klein JJ, Kerkoff AHM, van Herwaarden CLA. Evaluation of the effectiveness of four different inhalers in patients with chronic obstructive pulmonary disease. Thorax 1995;50(11):1183-1187.

11. Molimard M, Raherison C, Lignot S, Depont F, Abouelfath A, Moore N. Assessment of handling of inhaler devices in real life: an observational study in 3811 patients in primary care. J Aerosol Med 2003;16(3):249-254.

12. Van Beerendonk I, Mesters I, Mudde AN, Tan TD. Assessment of the inhalation technique in outpatients with asthma or chronic obstructive pulmonary disease using a metered-dose inhaler or dry powder device. $J$ Asthma 1998:35(3):273-279.

13. Hanania NA, Wittman R, Kesten S, Chapman KR. Medical personnel's knowledge and ability to use inhaling devices: metered-dose inhalers, spacing chambers, and breath actuated dry powder inhalers. Chest 1994; 105(1):111-116.

14. Lenney J, Innes JA, Crompton GK. Inappropriate inhaler use: assessment of use and patient preference of seven inhalation devices. EDICI. Respir Med 2000;94(5):496-500.

15. How to use puffers, inhalers, and other devices. Ottawa $(\mathrm{ON})$ : The Lung Association; [updated 2011 Apr 14; cited 2011 July 09]. Available from: www.lung.ca/diseases-maladies/help-aide/devices-dispositifs/index_e.php

16. Sestini P, Cappiello V, Aliani M, Martucci P, Sena A, Vaghi A, et al.; Associazione Italiana Pneumologi Ospedalieri Educational Group. Prescription bias and factors associated with improper use of inhalers. J Aerosol Med 2006;19(2):127-136

17. Advair Diskus ${ }^{\circledR}$ [package insert]. Research Triangle Park (NC): GlaxoSmithKline, Inc; 2011.

18. Advair HFA® [package insert]. Research Triangle Park (NC): GlaxoSmithKline, Inc; 2011

19. Spiriva ${ }^{\circledR}$ [package insert]. Ridgefield (CT): Boehringer Ingelheim Pharmaceuticals, Inc; 2011.

20. Symbicort ${ }^{\circledR}$ Turbuhaler ${ }^{\circledR} \quad$ [package insert]. Mississauga (ON): AstraZeneca Canada, Inc; 2011.

21. Hesselink AE, Penninx BW, Wijnhoven HA, Kriegsman DM, van Eijk JT. Determinants of an incorrect inhalation technique in patients with asthma or COPD. Scand J Prim Health Care 2001;19(4):255-260.

22. Wieshammer $S$, Dreyhaupt J. Dry powder inhalers: which factors determine the frequency of handling errors? Respiration 2008;75(1):18-25.
23. Dow L. Asthma in older people. Clin Exp Allergy 1998;28 Suppl 5:195-202.

24. Goodman DE, Israel E, Rosenberg M, Johnston R, Weiss ST, Drazen JM. The influence of age, diagnosis, and gender on proper use of metered-dose inhalers. Am J Respir Crit Care Med 1994;150(5 Pt 1):1256-1261.

25. Souza ML, Menghini AC, Ferraz E, Vianna EO, Borges MC. Knowledge of and technique for using inhalation devices among asthma patients and COPD patients. J Bras Pneumol 2009;35(9):824-831.

26. Bosnic-Anticevich SZ, Sinha H, So S, Reddel HK. Metered-dose inhaler technique: the effect of two educational interventions delivered in community pharmacy over time. J Asthma 2010;47(3):251-256.

27. Basheti IA, Armour CL, Reddel HK, Bosnic-Anticevich SZ. Long-term maintenance of pharmacists' inhaler technique demonstration skills. Am J Pharm Educ 2009;73(2):32.

28. Mickle TR, Self TH, Farr GE, Bess DT, Tsiu SJ, Caldwell FL. Evaluation of pharmacists' practice in patient education when dispensing a metereddose inhaler. DICP 1990;24(10):927-930.

29. O'Donnell DE, Aaron S, Bourbeau J, Hernandez P, Marciniuk DD, Balter M, et al. Canadian Thoracic Society recommendations for management of chronic obstructive pulmonary disease -2007 update. Can Respir J 2007;14 Suppl B:5B-32B.

30. Global strategy for the diagnosis, management, and prevention of chronic obstructive pulmonary disease. Bethesda (MD): Global Initiative for Chronic Obstructive Lung Disease (GOLD); 2009. 96 p.

31. Fink JB, Rubin BK. Problems with inhaler use: a call for improved clinician and patient education. Respir Care 2005;50(10):1360-1374.

32. Kesten S, Zive K, Chapman KR. Pharmacist knowledge and ability to use inhaled medication delivery systems. Chest 1993;104(6):1737-1742.

33. Burn CC, Pritchard JC, Whay HR. Effects of prevalence on observer agreement: a subjective assessment of working donkey behaviour as an example. In: Spink AJ, Ballintijn MR, Bogers ND, Grieco F, Loijens LWS, Noldus LPJJ, et al., editors. Proceedings of Measuring Behaviour 2008: 6th International Conference on Methods and Techniques in Behavorial Research; 2008 Aug 26-29; Maastricht (Netherlands). Wageningen (Netherlands): Noldus; 2008. p. 197-198.

34. Chapman KR, Love L, Burbaker H. A comparison of breath-actuated and conventional metered-dose inhaler inhalation techniques in elderly subjects. Chest 1993;104(5):1332-1337.

35. Dewar MH, Jamieson A, McLean A, Crompton GK. Peak inspiratory flow through turbuhaler in chronic obstructive airways disease. Respir Med 1999;93(5):342-344.

36. Broeders ME, Molema J, Hop WC, Vermue NA, Folgering HT. The course of inhalation profiles during an exacerbation of obstructive lung disease. Respir Med 2004;98(12):1173-1179.

37. McCarney R, Warner J, Iliffe S, van Haselen R, Griffin M, Fisher P. The Hawthorne effect: a randomised, controlled trial. BMC Med Res Methodol 2007;7:30.

Joshua Batterink, BSC(Pharm), ACPR, is a Clinical Pharmacist with Providence Health Care, St Paul's Hospital, Vancouver, British Columbia.

Karen Dahri, PharmD, ACPR, is a Pharmacotherapeutic Specialist with CSU Pharmaceutical Sciences, Vancouver Coastal Health, Vancouver, British Columbia.

Amneet Aulakh, PharmD, ACPR, is a Pharmacotherapeutic Specialist, CSU Pharmaceutical Sciences, Vancouver Coastal Health, Vancouver, British Columbia.

Carmen Rempel, RRT, CRE, is the Asthma and COPD Education Coordinator, Department of Medicine-Respiratory, Vancouver Coastal Health, Vancouver, British Columbia.

\section{Address correspondence to:}

Joshua Batterink

Providence Health Care

St Paul's Hospital

1081 Burrard Street

Vancouver BC V6Z1Y6

e-mail: jbatterink@providencehealth.bc.ca 